Original Research Paper

\title{
Conceptual Interpretation of Modern Value Policy in the Context of Scientific Research Practices
}

\author{
${ }^{1}$ Vagif Deirushevich Bairamov, ${ }^{2}$ Yulia Igorevna Isakova, ${ }^{3}$ Aues Mukhamedovich Kumykov, \\ ${ }^{4}$ Anatoly Vladimirovich Lubsky and ${ }^{4}$ Yury Grigorievich Volkov \\ ${ }^{I}$ Moscow State University of Humanities and Economics, Moscow, Russia \\ ${ }^{2}$ Don State Technical University, Rostov-on-Don, Russia \\ ${ }^{3}$ Kabardino-Balkarian State University, Nalchik, Russia \\ ${ }^{4}$ Southern Federal University, Rostov-on-Don, Russia
}

Article history

Received: 28-12-2015

Revised: 14-04-2016

Accepted: 18-04-2016

Corresponding Author: Anatoly Vladimirovich Lubsky Southern Federal University, Rostov-on-Don, Russia Email:n_lav@mail.ru

\begin{abstract}
As part of the research a conceptual interpretation of research practices witnessed an essential condition for value policy as a factor of state administration efficiency as well. Following the results of a sociological study conducted by the authors, a hierarchical structure of value policy efficiency in the Russian Federation has been presented based on the criteria of significance and satisfaction level of public values in modern society. The level of the cumulative efficiency of modern value policy at the present stage of its implementation has been determined quantitatively and qualitatively. The optimal structure of value policy and state efficiency in Russian society has been substantiated, the basic public values of which should become a group of public values. It has been found that the legal and moral public values are secondary to social ones and represent public values of a higher level in today's society in the Russian Federation as well. This approach will be the basis for improving the theoretical basis of value policy. It will serve as a fundamental basis for improving state administration in the Russian Federation.
\end{abstract}

Keywords: Sociology, Public Value, Value Policy Efficiency, State Administration, Society, Public Nature

\section{Introduction}

In modern conditions the state administration system in Russia is undergoing society pressure which is subject to ever-increasing demands of socialization about efficiency of administration, social justice, expanding civic engagement (Lukin and Musiyenko, 2015). The hegemony of the economic concept in state administration provoked by the implementation of managerial administrative reforms determines the need to improve policy efficiency as management activity as well (Volkova, 2013). Social conditions necessitate the formation of a new scientific-theoretical and practical vector of improving the state administration system with a focus on the human potential maintenance, ensuring society stability and the necessary continuity in its development. The value policy acts as a unifying principle, as it is formed by public discussion and refers to all citizens in a democratic state without exception
(Cunningham, 2015). The state administration function is the basis of formation of an optimum balance of the state, the society and personality interests, the harmonized criterion of which serves one or another public value. Public values are a major component of social cohesion within the axiological turn in state management (Griffiths, 2014). The signs of political administration should be a focus on a socially important problem, public nature, the possibility of choice of alternative ways of implementing the claimed socially significant value (social justice, liberalism, democracy, etc.). Orientation and accounting of public values provides the state administration efficiency as they determine the public space and contribute to the public benefit achievement.

Radical reforms on the basis of value policy were implemented in such countries as the USA, Canada, Australia, Great Britain, Denmark, New Zealand, as well as in Norway and Sweden (Qian et al., 2015). As a result 
of the positive effect of the practical introduction of value policy is the highest level of state administration efficiency worldwide out of 215 states under study (WGI, 2015). Based on the global ranking of countries according to the state administration efficiency criterion, since 1996 the Russian Federation belongs to the countries with low efficiency of public administration and at the beginning of 2015 it was estimated at -0.08 (within -2.5 and 2.5 ratings) (WGI, 2015). In this connection, it seems appropriate to conceptually interpret the value policy based on its efficiency assessment at the present stage of its implementation and the formation of a democratic state in the Russian Federation in the framework of sociological approach.

\section{Literature Review}

In modern sociology in studies of cultural and political processes a true axiological "renaissance" is taking place which significantly transforms both modern science and state administration system (Kilburn, 2009; Witesman and Walters, 2014). A critical approach to the new paradigm of state management is accompanied by development of the "public values management" concept. In the fundamental basis of the concept there is a scientific focus-the value policy based on harmonizing the public policy in the development strategy implementation and basic values system in a social environment (Jaapar et al., 2012). At that public values are formed during public discussions with the direct participation of the state.

Value policy as a special kind of administrative activity is based on public values. As the terminology analysis shows that there are different approaches to understanding the essence of public values in the scientific sociological discourse. For example, some scientists consider public values as "deep-rooted ideas on what is good and what is bad" (Nabatchi, 2012). That is public values are understood as something more than public goods, public interest or just public benefit (Cutler, 2015).

There is also some other scientific point view of the public values content, by which "the limits determining interactions in public policy, collective needs of citizens, formed during the civil communication are meant"(Volkova, 2013).

But meanwhile, in terms of differentiation of conceptual approaches to understanding the essence of public values, scientists are unanimous in recognition of their binary nature. The binarity is evident in that value policy as a management activity can be carried out not only based on the current state of unconscious and conscious public values, but also purposefully transformed into informed structures of public values in a context of dialogue between the state and society
(Beck and Bozeman, 2007). That is, the public values are not everything that is presented in public discourse, but that is of the nature of mandatory requirements for the state administration system and the organization of interactions in the public field and has a positive meaning (Morselli and Passini, 2015). Public values cannot be formed without the state participation, provided that it does not impose its priorities on society, but attracts citizens for cooperation (Volkova, 2013). Sociologies emphasize that the value $s$ cannot be considered public only on the grounds that it is determined by government organizations. Public value should be recognized by all citizens together, but not individuals (Sommerfeldt, 2013). In this regard, the ability to identify and validate the appropriate public values, to resolve value conflicts, to favor the formation of collective public values, preventing "value gap" in the society is recognized as the basis of efficient value policy (Zhuravleva, 2015).

Modern sociological theory is also characterized by a critical approach to value policy as a form of management. The criticism was based on categoricalness, monologicalness and ideologicalness. "Axiological policy-as critics say-suggests that some things were settled outside the political process and thus, policy becomes the means for the implementation of a priori positions. Its ideologicalness suggests that the answers have already been found ... Axiological policy denigrates political subjectivity of actors, whether they are individuals, groups or state as a whole" (Sakwa, 2014). Critics oppose the dialog policy to the axiological policy in which pluralism of political participation in the political process is essential (Blewitt, 2015).

Such critical attitude to value policy has a good reason, if it is understood as a policy just taking into account public values (Papanastasiou and Koutselini, 2003). However, in the neoclassical model of state administration value policy is a special kind of management, which not only focuses on public values, but also forms them as a basis efficient state administration. This idea of value policy suggests the political subjectivity of state administration actors as a prerequisite of value policy (Blewitt, 2015).

Thus, based on literature review of scientific practices of value policy it can be interpreted that in modern sociology theory the value policy paradigm development is one of the most influential ideologies in the state administration system. Value policy based on humanitarian technologies leads to the fact that citizens are increasingly seeking to shape the political state orientation that causes blurring of the boundaries between the state and civil society, thereby improving state administration efficiency (Volkova, 2013). 
Based on the understanding of value policy as a particular form of management practice, this study aims at conceptual interpretation of depending state administration system efficiency on value policy, the formation of the optimal structure of value policy and state efficiency by taking into account the importance of the value policy priority in Russian society

\section{Methods and Techniques}

The basis of the study to determine the efficiency of value policy and Russia were the sociological survey results on determining the importance of prioritizing values and the level of their provision in the state (the level of satisfaction). The respondents were young people. The choice of the category of respondents is argued by the fact that in modern conditions the expanding range of possibilities for self-realization of young people both in political and other spheres of social life gains particular importance (Tyutin, 2014). This in turn is a precondition for closer cooperation of youth with the state power, creates conditions for sustainable cooperation between the society and the state (Nikovskaya and Yakimets, 2015). As the experience of recent decades shows, it is those states which achieve significant results in the society democratization that pay more attention to creation and meeting youth public values. Sustainable development is demonstrated precisely by those societies which have reviewed the system of traditional views on the new generation, on the system of relations between the generations and the importance of their social values in the political and socio-economic development. Obviously, those states and societies will have the strategic advantages, which learn to effectively use the human potential and, above all, the development of the innovative potential belonging to the youth (Nikovskaya and Yakimets, 2015).

Most of the students of youth organizations in the process of studying various political, economic and legal aspects as the problem situation indicator (the object of analysis) serve, as a rule, young adults, fully incorporated in the social labor division (Smorgunov and Volkova, 2014). In this regard, within the study the information field is limited to the 20-30 years age range of the respondents in the sociological survey.

The sample size of respondents, sufficient for sociological research and extrapolation to the whole sociological sample is determined from the formula:

$S S=\frac{Z(\alpha)^{2} \cdot p \cdot(1-p)}{\varepsilon^{2}}$

Where:

$S S=$ Sample amount
$Z(\alpha)=$ Standard deviation determined according to the selected level of confidence (determined according to Table 1)

$\alpha=$ Confidence level

$\mathrm{p} \quad=$ Sample variation

$\varepsilon \quad=$ Acceptable level of error (Burova et al., 2014)

Sociological survey was carried out by a formalized interviewing via the Contacts social network on the basis of recording the responses to closed questions of formed questionnaires. The advantage of this method despite the high consumption of time and money is that it makes possible to improve the reliability of the data collected by reducing the number of non-responding persons and errors when filling out questionnaires.

Also during the sociological research the results were partially recorded on a "snowball" principlewhen the one who was recommended by the previous participant was connected to the number of respondents and the previous participant was confident in his/her answer.

Closed questionnaires formed by submitting a list of public values which the respondents were asked to rate according to the criterion of significance in the process of their socialization on a scale from 1 to 10 for each and the criterion of meeting this value in the society in percent according to the achievement degree of $1 \%$ to $100 \%$ for each of them.

The system of public value of youth was formed on the basis of literary generalizations (Kenter et al., 2015; Martin and Upham, 2015; Petrova-Gjorgjeva, 2010).

The assessment technology of state value policy efficiency involves determining of prioritizing of value and the degree of their satisfaction, the calculation of the measured total efficiency and its interpretation due to the interval scale.

The priority of value significance is determined on the basis of the point assessment of respondents from formulas (2-3):

$$
\begin{aligned}
& P_{p i}=\sqrt[n]{\prod_{i=1}^{n} a_{i j}} \\
& P_{i}=P_{p i} / \sum_{i=1}^{n} P_{p i}
\end{aligned}
$$

Where:

$P_{p i}=$ Priority average score of the $\mathrm{i}_{-}{ }^{\text {th }}$ value

$P_{i}=$ Normalized priority of the $\mathrm{i}_{-}{ }^{\text {th }}$ value

$a_{i j}=$ Score value of the ${\mathrm{i}-{ }^{\text {th }}}$ and $\mathrm{j}^{\text {th }}{ }^{\text {th }}$ respondent. Scores are from 1 to 10 , wherein 10 is the highest priority

$n \quad=$ Number of respondents (Larichev, 2013) 
Table 1. Standard deviation value

\begin{tabular}{lllllllll}
\hline$\alpha, \%$ & 60 & 70 & 80 & 90 & 95 & 97 & 99 & 99.7 \\
\hline$Z$ & 0.84 & 1.03 & 1.29 & 1.65 & 1.96 & 2.18 & 2.58 & 3.00 \\
\hline
\end{tabular}

The degree of satisfaction according to the value $\left(C_{i}\right)$ is determined as the average percentage of satisfaction for respondents. (4-6):

Value policy efficiency is determined from formulas

$$
\begin{aligned}
& E=\sum_{i=1}^{n}\left[P(V G)_{i} \cdot C(V G)_{i}\right] \\
& P(V G)_{i}=\sum_{i=1}^{n} P_{i} \\
& C(V G)_{i}=\frac{\sum_{i=1}^{n} C_{i}}{n}
\end{aligned}
$$

Where:

$$
\begin{array}{ll}
P(V G)_{I} & =\text { Priority of the } i^{\text {th }} \text { value group } \\
C(V G)_{I} & =\text { Satisfaction degree in the } i-^{\text {th }} \text { value group } \\
P_{i} & =\text { Priority of the } i{ }^{\text {th }} \text { value } \\
C_{i} & =\text { Satisfaction degree of the } i-{ }^{\text {th }} \text { value } \\
N & =\text { Number of value groups (Larichev, 2013) }
\end{array}
$$

To determine the efficiency levels of state value policy, the Fibonacci law was used, according to which the intervals of the values of performance levels are defined by the system (Formula 7):

$$
\left\{\begin{array}{c}
E_{\text {min }} \leq E \leq E_{1} \\
E_{1}<E \leq E_{2} \\
E_{2}<E \leq E_{\text {max }} \\
E_{1}=E_{\text {min }}+0,38\left(E_{\text {max }}-E_{\text {min }}\right) \\
E_{2}=E_{\text {min }}+0,62\left(E_{\text {max }}-E_{\text {min }}\right)
\end{array}\right.
$$

Where:

$$
\begin{aligned}
E_{\min } & =\text { Minimum value of efficiency indicator } \\
E_{\max } & =\text { Maximum value of efficiency indicator; } \\
{\left[E_{\min } ; E_{1}\right]=} & \text { Interval of low values of efficiency } \\
& \text { indicator; } \\
\left(E_{1} ; E_{2}\right]= & \text { Interval of middle values of efficiency } \\
& \text { indicator; } \\
\left(E_{2} ; E_{\text {max }}\right]= & \text { Interval of high values of efficiency } \\
& \text { indicator (Vorobiev, 2011) }
\end{aligned}
$$

\section{Results}

At the beginning of 2015 the number of Russian population aged 20-30 amounted to 21,913 thousand people (FSSS, (2015). Since it is a large totality by size ( $>30$ pers.), with the aim of narrowing the number of respondents the sufficiency of sample totality is determined according to formula 1. Allow that the valid level of confidence coefficient at which the research results are representative and statistically significant, is considered to be $90 \%(\alpha=90 \%)$, the confidence interval is $\pm 5 \%$ (Burova et al., 2014). For given characteristics the sample size, in which the results of sociological survey of Russian youth would be representative, reached 273 people.

Based on the processing of the results of the closed questionnaire the average score for each type of public value was determined (Formula 2).

Based on the middle scores of significance priority of public values for the Russian youth the normalized priority value was identified as the sum of priorities of public values within the designated sampling of public values.

Also based on the results of the survey the degree of achievement (satisfaction) for each type of public value was identified (Formula 3).

The results of the sociological research are summarized in Table 2.

In purpose to determine the level of value policy efficiency the public values are integrated into the three groups of values according to the nature of their formation:

- Social public values: Security, peace, order and stability

- Legal public values: Human rights, legitimacy, freedom, justice, private property, equality and democracy

- Moral public values: Patriotism, individual initiative, solidarity, tolerance, traditionalism, teamwork, responsibility, citizenship and trust

The level of value policy efficiency is calculated on the basis of formulas 4-6. The results are shown in Table 3.

Since the component constituting value policy efficiency, priority and satisfaction, take values from 0 to 1 , the interval of levels of state value policy efficiency is represented in the range $[0 ; 1]$. Using Formula 7 the interval of low values of value policy efficiency is calculated in the range $[0 ; 0.38]$, the interval of middle values- $[0.38 ; 0.62]$, the interval of high values- $[0.62 ; 1]$. 
Table 2. Summary of the results of the sociological survey of Russian youth related to the importance of prioritizing public values and the level of their achievement

\begin{tabular}{|c|c|c|c|}
\hline Public value & $\begin{array}{l}\text { Priorities of significance } \\
(\text { score } 1-10)\end{array}$ & $\begin{array}{l}\text { Priority significance } \\
\text { normalized (share) }\end{array}$ & $\begin{array}{l}\text { Degree of } \\
\text { achievement (share) }\end{array}$ \\
\hline Procedure & 10.0 & 0.0810 & 0.631 \\
\hline Security & 9.7 & 0.0786 & 0.622 \\
\hline Human rights & 9.3 & 0.0754 & 0.623 \\
\hline Legality & 9.1 & 0.0737 & 0.646 \\
\hline Peace & 8.8 & 0.0713 & 0.615 \\
\hline Freedom & 8.4 & 0.0681 & 0.574 \\
\hline Justice & 7.9 & 0.0640 & 0.541 \\
\hline Stability & 7.7 & 0.0624 & 0.404 \\
\hline Patriotism & 7.5 & 0.0608 & 0.914 \\
\hline Private property & 7.1 & 0.0575 & 0.776 \\
\hline Equality & 6.9 & 0.0559 & 0.472 \\
\hline Private initiative & 6.7 & 0.0543 & 0.681 \\
\hline Democracy & 6.1 & 0.0494 & 0.383 \\
\hline Solidarity & 5.7 & 0.0462 & 0.686 \\
\hline Tolerance & 4.8 & 0.0389 & 0.642 \\
\hline Traditionalism & 4.5 & 0.0365 & 0.748 \\
\hline Collectivism & 3.2 & 0.0259 & 0.651 \\
\hline
\end{tabular}

Table 3. Estimated assess of the value policy efficiency level at the present stage of its implementation

\begin{tabular}{lllll}
\hline Public value group & $\begin{array}{l}\text { Normalized } \\
\text { priority significance }\end{array}$ & $\begin{array}{l}\text { Degree of } \\
\text { achievement }\end{array}$ & $\begin{array}{l}\text { Contributing to the formation of } \\
\text { the value policy efficiency, (share) }\end{array}$ & $\begin{array}{l}\text { Contributing to the formation } \\
\text { of the value policy efficiency, (\%) }\end{array}$ \\
\hline Social & 0.293400 & 0.558816 & 0.163932 & $27.28 \%$ \\
Legal & 0.444100 & 0.561202 & 0.249221 & $41.48 \%$ \\
Moral & 0.262600 & 0.714890 & 0.187702 & $31.24 \%$ \\
Sum & 0.600854 & $100 \%$ & & \\
\hline
\end{tabular}

\section{Discussion}

Based on the undertaken study, using the results of sociological survey, as a conceptual interpretation of value policy the decomposition of hierarchical structure of value policy efficiency in Russia in modern conditions was developed (Fig. 1). The constituent elements of which are the main public values of the Russian youth:

- L0, L1, L2-hierarchical levels

- E-value policy efficiency assessment

- VG-groups of public values

- VG1 - social values

- VG2 - legal values

- VG3 - moral values

- V-public values

- $\mathrm{V} 1$ - security

- V2-peace

- V3 - order

- V4-stability

- V5 - patriotism

- V6 - individual initiative

- V7 - solidarity

- V8 - tolerance

- V9-traditionalism

- V10 - collectivism

- V11 - human rights
- $\quad \mathrm{V} 12$ - legitimacy

- V13 - freedom

- V14 - justice

- V15 - private property

- V16 - equality

- V17 - democracy

- $\quad \mathrm{P}$ - priority of values and groups of values

- $\mathrm{C}-$ level of value satisfaction

The first level (L0) is the highest one; it characterizes the overall value policy efficiency. The second level (L1) reflects the value policy efficiency at the level of each group of public values of Russian youth. The third level (L2) allows analyzing the value policy efficiency at the level of each public value indicated in the sociological research sample.

Based on the hierarchical structure of value policy in Russia it can be testified that the most significant contribution to the implementation of modern value policy makes a group of legal public values. Nowadays it determines the value policy efficiency in Russia by $41.48 \%$. In general, it should be noted that today legal public values are satisfied by the state power of Russia at only $56.1 \%$. The lowest level of achievement can be traced in meeting the requirements of democracy $(38.3 \%)$, the highest level-in the rights of private property $(77.6 \%)$. 


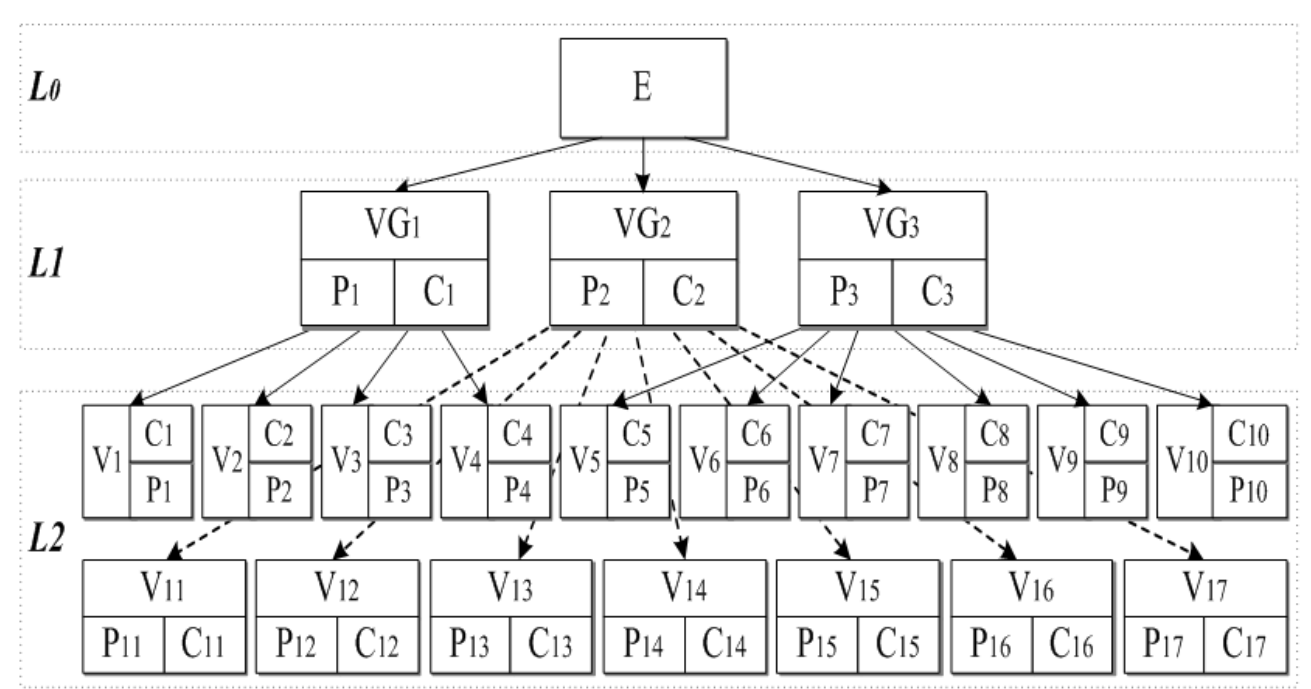

Fig. 1. Decomposition of hierarchical structure of value policy efficiency

After legal public values in Russian society moral public values determine the value policy efficiency. The level of their impact is estimated at $31.24 \%$. The most important for the youth moral public value is patriotism $(7.5 \%)$. A positive aspect is the highest level of satisfaction in the society of this public value- $91.4 \%$.

The lowest level of achievement is characterized by such moral public value as tolerance- $62.4 \%$.

Providing satisfaction of moral public values in the present conditions is characterized by the highest level of achievement of all groups of public values of Russian society- $71.5 \%$.

The lowest impact on the realization of value policy has a social group of public values- $27.28 \%$ at the lowest level of their satisfaction in the society by $55.9 \%$. One of the most crucial current values in society is the order, the level of significance of which is estimated at a maximum score of " 10 ". At the same time, it is characterized by a rather low level of its achievement in modern conditions by $63.1 \%$. It should be noted that social public values are the most important values for the Russian society, while the level of their satisfaction today is a minimum.

Overall, the cumulative value policy efficiency in the Russian society is estimated at the level of 0.600854 , which characterizes it as a policy with an average efficiency.

Given these premises, it can be stated that in order to improve the efficiency system of state administration in the Russian Federation the conceptual model of value policy should have a hierarchy of implementation of the formation, registration and meeting public values in the direction from social public values to legal and moral ones.

\section{Conclusion}

Therefore, the conceptual interpretation of public management research practices in the context of the sociological approach has testified that the basis for the increase of state administration efficiency in modern conditions is the ability of the state to generate, identify the society public values and define their hierarchical structure of achievement. By generalization of sociological literary studies it is concluded that the public value system is generated in the course of close cooperation of the state and society by implementing state value policy in the process of public socialization of the society. Based on the results of sociological survey of respondents it was found that the current practice of value policy in the Russian Federation reflects the average level of state administration efficiency. The hierarchical structure of value policy efficiency has identified that a fundamental component of state value policy in the Russian society as exemplified by the youth at the present stage of its implementation is to meet a group of legal public values. As part of the conceptual interpretation of public management research practices and accounting the significance priorities of public values in modern Russian society it has been justified the following: The basis of value policy should be achievement of satisfaction of social public values as a base in the society, in order to achieve public values of a higher order-legal and moral. Such an approach would increase the level of state administration efficiency taking into account the consistency of interests of the society and the state. This will contribute to maximize the satisfaction of social needs and the general welfare growth. 
The presented formalization of the priority structure to meet the public values of the society socialization in the process of formation and implementation of state value policy will be the basis for improving the public management paradigm within a sociological approach, as it considers the self-development of environment, determine progressiveness of sociological views in solving complex theoretical and practical problems of natural science.

\section{Acknowledgement}

We thank our unknown reviewers for their review and comments that greatly improved the manuscript.

\section{Author's Contributions}

Vagif Deirushevich Bairamov: Developed the conceptual idea and design of the research work.

Yulia Igorevna Isakova: Arranged questionnaire survey, participated in the results analysis, contributed to the drafting of the article.

Aues Mukhamedovich Kumykov: Arranged questionnaire survey, provided critical research reviewing for significant intellectual content.

Anatoly Vladimirovich Lubsky and Yury Grigorievich Volkov: Contributed to the questionnaire survey, discussion of the results and drafting of the article.

\section{Ethics}

This article is original and contains unpublished materials. The corresponding author confirms that all of the other authors have read and approved the manuscript and there are no ethical issues involved.

\section{References}

Beck, J.T. and B. Bozeman, 2007. Public values: An inventory. Admin. Soc., 39: 354-381. DOI: $10.1177 / 0095399707300703$

Blewitt, J., 2015. Sustainability: A dialog of values. Int. Encycl. Soc. Behav. Sci., 2: 794-800.

Burova, N.V., E.K. Vasilieva and I.I. Eliseeva 2014. Social Statistics. 1st Edn., Finance and Statistics, Moscow.

Cunningham, F., 2015. Democratic theory. Int. Encycl. Soc. Behav. Sci., 2: 90-96. DOI: 10.1016/B978-0-08-097086-8.93032-0

Cutler, T., 2015. New Managerialism and new public sector. Manage. Int. Encycl. Soc. Behav. Sci., 2: 770-775.

FSSS, 2015. Federal state statistics service.

Griffiths, M., 2014. The affective spaces of global civil society and why they matter. Emotion Space Soc., 11: 89-95.

DOI: $10.1016 /$ j.emospa.2013.08.003
Jaapar, A., N.A. Maznan and M. Zawawi, 2012. Implementation of value management in public projects. Proc. Soc. Behav. Sci., 68: 77-86. DOI: $10.1016 /$ j.sbspro.2012.12.208

Kenter, J.O., L. O'Brien, N. Hockley, N. Ravenscroft and I. Fazey et al., 2015. What are shared and social values of ecosystems? Ecol. Econom., 111: 86-99. DOI: $10.1016 /$ j.ecolecon.2015.01.006

Kilburn, W.H., 2009. Personal values and public opinion. Soc. Sci. Q, 90: 868-885. DOI: $10.1111 /$ j.1540-6237.2009.00667.x

Larichev, O.I., 2013. Theory and Methods of DecisionMaking. 1st Edn., Universitetskaya Kniga, Moscow.

Lukin, V. and T. Musienko, 2015. Theory of change of values: Research models. J. Club "Interlos "CreadoNew".

Martin, C.J. and P. Upham, 2015. Grassroots social innovation and the mobilisation of values in collaborative consumption: A conceptual model. J. Cleaner Product. DOI: $10.1016 /$ j.jclepro.2015.04.062

Morselli, D. and S. Passini, 2015. Value-oriented citizenship index: New extensions of Kelman and Hamilton's theory to prevent autocracy. Soc. Sci. Res., 54: 289-302. DOI: $10.1016 /$ j.ssresearch.2015.08.006

Nabatchi, T., 2012. Putting the "Public" back in public values research: Designing participation to identify and respond to values. Public Admin. Rev., 72: 699-708. DOI: 10.1111/j.1540-6210.2012.02544.x

Nikovskaya, L.I. and V.N. Yakimets, 2015. Towards consistency of public policy institutes. Power, 6: 16-22.

Papanastasiou, C. and M. Koutselini, 2003. Developmental model of democratic values and attitudes toward social actions. Int. J. Educ. Res., 39: 539-549. DOI: 10.1016/j.ijer.2004.07.003

Petrova-Gjorgjeva, E., 2010. Democratic society and moral education. Proc. Soc. Behav. Sci., 2: 5635-5640. DOI: $10.1016 /$ j.sbspro.2010.03.919

Qian, S., Y. Liu and S. Galam, 2015. Activeness as a key to counter democratic balance. Phys. A: Stat. Mechan. Applic., 432: 187-196.

Sakwa, R., 2014. Value policy Vs dialog policy in modern Europe. Polis. Politicheskie Issledovaniya, 2: 8-17.

Smorgunov, L.V. and A.V. Volkova, 2014. Public values and Public Administration. 1st Edn., Aspect Press, Collective Monograph. Moscow.

Sommerfeldt, E.J., 2013. The civility of social capital: Public relations in the public sphere, civil society and democracy. Public Relat. Rev., 39: 280-289. DOI: 10.1016/j.pubrev.2012.12.004

Tyutin, D.V., 2014. Evolution of new public administration: Logics of efficiency, productivity and public value management. Theory Pract. Public Dev., 5:179-181. 
Volkova, A.V., 2013. Public Values and Public Administration System in Russia. 1st Edn., SpbSU Press, St. Petersburg.

Vorobiev, N.N., 2011. The Fibonacci Sequence. 1st Edn., Nauka, Fizmalit, Moscow.

WGI, 2015. The Worldwide Governance Indicators Project.
Witesman, E. and L. Walters, 2014. Public service values: A new approach to the study of motivation in the public sphere. Public Admin., 92: 375-405. DOI: $10.1111 /$ padm. 12000

Zhuravleva, I.V., 2015. Institutions of civil society in space of democratic politics. Proc. Soc. Behav. Sci., 166: 546-551. DOI: 10.1016/j.sbspro.2014.12.570 